\title{
A rare case of Solitary Fibrous Tumor of Subglottis
}

\section{Sumana CV ${ }^{1}$, Suhel Hasan ${ }^{1}$, Betty Mariam Jacob ${ }^{1}$ and Rajeswarie $\mathrm{RT}^{2}$}

Received: 12 May, 2020

Accepted: 29 May, 2020

Published: 30 May, 2020

*Corresponding author: Sumana CV, Department of ENT, Mazumdar Shaw Medical Centre, Narayana Hrudayalaya Ltd, Bangalore, Karnataka, India, Tel: +91 9886853071; E-mail: sumanacv84@gmail.com

Keywords: Solitary fibrous tumor; Subglottis; Larynx

https://www.peertechz.com

Check for updates

'Department of ENT, Mazumdar Shaw Medical Centre, Narayana Hrudayalaya Ltd, Bangalore,

Karnataka, India

${ }^{2}$ Department of Pathology, Mazumdar Shaw Medical Centre, Narayana Hrudayalaya Ltd, Bangalore,

Karnataka, India

\begin{abstract}
Solitary Fibrous Tumor is a rare benign mesenchymal tumor, described as a primary pleural lesion. $50 \%$ of the cases are seen in the thorax and only $6 \%$ develop in the head and neck region. Laryngeal involvement is rare, mostly involving the supraglottic larynx. We report a case of Solitary fibrous tumor of the subglottic larynx, which displayed positivity to Immunohistochemical marker CD34, and was excised surgically by an external approach.
\end{abstract}

\section{Introduction}

Solitary fibrous tumor(SFT) is a rare mesenchymal tumor which is usually of a benign nature. It was first described by Klemperer and Rabin in 1931, as a primary pleural lesion [1]. About $50 \%$ of the cases of SFT are seen in the thorax, but only $6 \%$ of the cases develop in the head and neck region [2]. Laryngeal involvement is very rare with only a few cases reported in the literature, out of which most of them were found to be involving the supraglottis/glottis.

We hereby present a case of SFT involving the subglottis. To the best of our knowledge, this is the third such case of SFT of the subglottis, reported in the literature.

\section{Case report}

A 35 year old female, non smoker, presented with the complaints of difficulty in breathing and hoarseness since a year. She developed noisy breathing since 6 months. She had previously consulted a few physicians and was treated as a patient of Bronchial Asthma. She had no complaints of cough, fever, dysphagia or loss of weight. She was in mild stridor at the time of presentation. On Videolaryngoscopic examination, a smooth subglottic mass with prominent vessels on the surface, was seen obstructing her airway significantly (about 90\%), with a broad attachment on the anterior wall of subglottis.
Her Vocal cords were mobile on both sides with a phonatary gap, as a result of the mass protruding into the glottis during phonation (Figure 1).

Contrast enhanced CT of the neck showed an intensely enhancing subglottic mass without erosion of the cartilages(Figure $2 \mathrm{~A}, \mathrm{~B}$ ). As the patient did not show any clinical or radiological features of malignancy like erosion of cartilage or lymph node metastasis, a clinico-radiological diagnosis of Subglottic vascular benign lesion- probably a Haemangioma, was made.

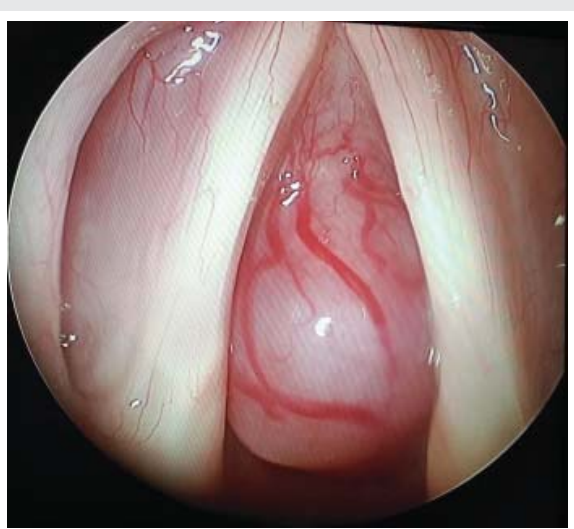

Figure 1: Endoscopic picture of the subglottic vascular lesion. 
She was planned for surgery. Considering the narrow airway with a highly vascular lesion, we planned to do a prior tracheostomy, and excise the mass by an external approach. Since the lesion was highly vascular and sessile with a broad attachment to the anterior subglottic mucosa, Oral Microlaryngeal Laser Excision was not considered. Aiming the Laser beam to an anterior broad subglottic attachment would have been technically challenging. Hence we chose an external approach, as we could accomplish better exposure of the lesion, with good subglottic mucosal preservation and vascular control, avoiding injury to the cricoid cartilage. Tracheostomy was done under Local Anaesthesia. She was subsequently induced and under General Anaesthesia, a horizontal skin crease incision was made at the level of the cricothyroid membrane. After raising the flaps and dissecting the strap muscles, mass was exposed by entering through the cricothyroid membrane and gently retracting cricoid and thyroid cartilages(Figure 3). Mass was removed in toto, with a margin of $1 \mathrm{~mm}$, under good haemostatic control. Complete removal was re confirmed by Direct Laryngoscopy examination. Wound was closed in layers with a small glove drain in place.

On microscopic examination, lesion was variably cellular spindle cell neoplasm, composed of peripheral hypocellular myxoid areas and central cellular spindle cell areas composed of tumor cells in fascicles. A diagnosis of Solitary Fibrous Tumor was made, based on Histopathology and Immunohistochemistry. The lesion was positive for $\mathrm{CD} 34$ and negative for SMA,S100, Desmin, Cytokeratin, CD31 and CD99 (Figures 4-6). There were no histological features of malignancy and margin was free of the lesion.
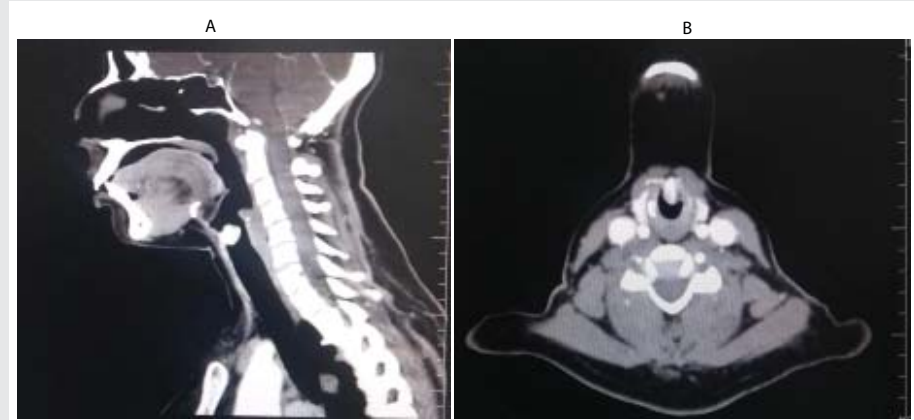

Figure 2A,B: Contrast enhanced CT of the neck, A-Sagittal and B- Axial section showing intensely enhancing subglottic lesion.

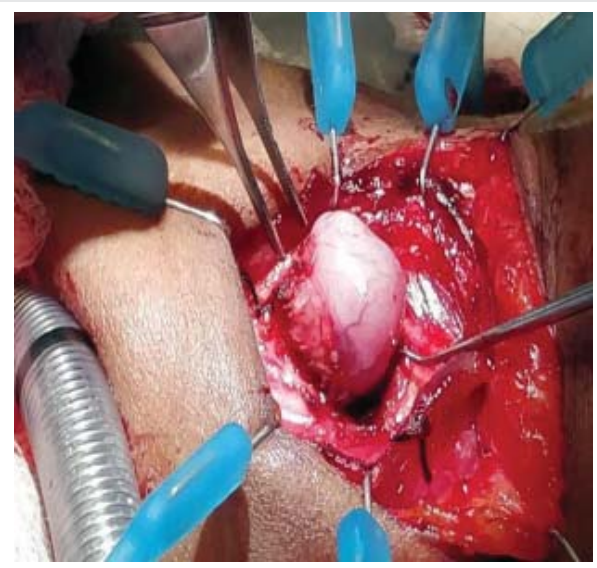

Figure 3: Removal of the lesion through the cricothyroid membrane.

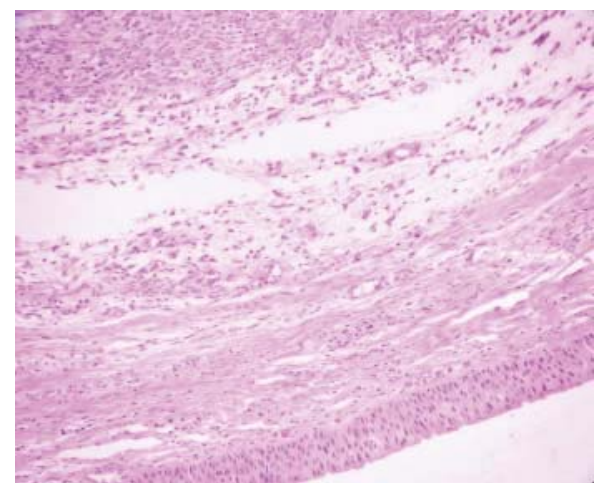

Figure 4: Photomicroscopy showing nodular lesion lined by respiratory epithelium(H\&E x 400)

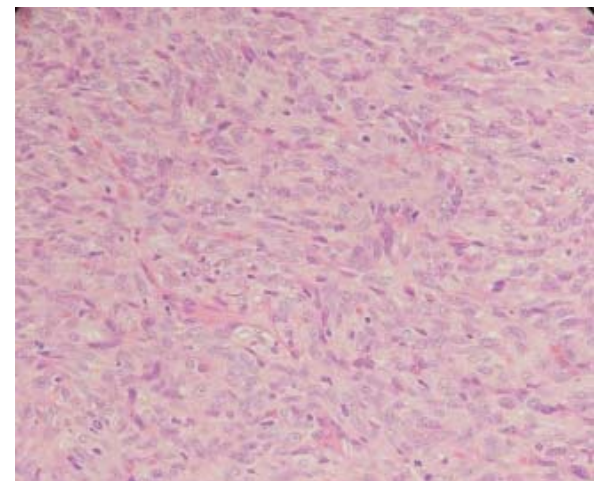

Figure 5: Photomicroscopy showing Spindle cell lesion with Haemangiopericytomaike area.

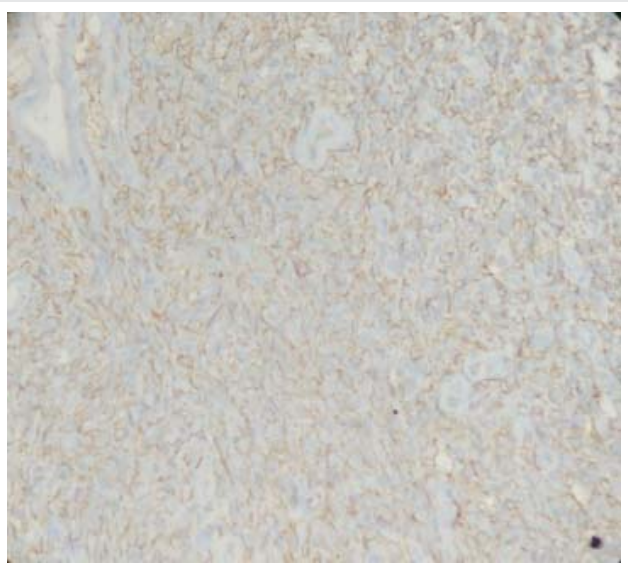

Figure 6: CD34 Positive.

Clinically it is difficult to distinguish between a benign and malignant Solitary Fibrous tumour. Our patient had a smooth, well circumscribed, vascular lesion, which was slow growing, showing no features of cartilage erosion or regional metastasis, which was more in favour of a benign lesion. As a precautionary measure, a safety margin of $1 \mathrm{~mm}$ was included during excision. Regular follow up is essential to identify local recurrences or any possible malignant transformation.

Patient was reviewed after a week. She was asymptomatic with a good voice and subglottic mucosa had healed well(Figure 7). She was then decannulated and was advised to be under regular follow up. 


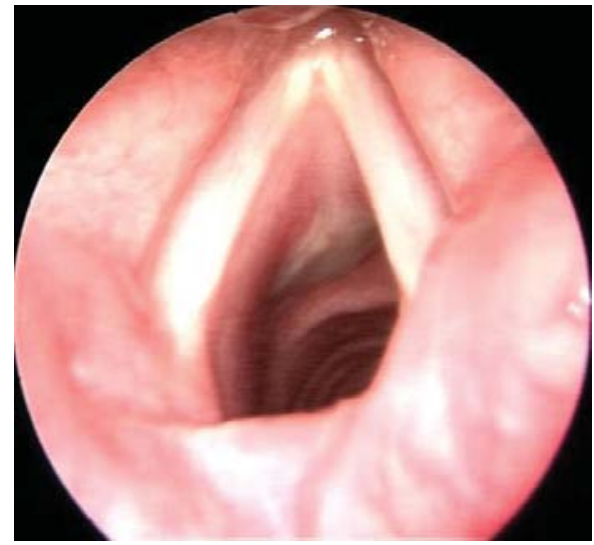

Figure 7: Endoscopic picture showing well healed subglottic mucosa on post op day 7.

\section{Discussion}

Solitary fibrous tumor(SFT) is a rare benign mesenchymal tumor, also known as benign localised mesothelioma, submesothelioma and subserosal fibroma, that arises from the pleura and other serosal membranes [3]. About $50 \%$ of SFTs arise in the thorax. They occasionally also develop in the extrathoracic spaces like the liver, pancreas, spleen, retroperitoneum and extracranial head and neck regions, such as the oral cavity, orbit, nasal cavity, parapharyngeal space, infratemporal fossa and others [4-6]. 6\% of SFTs arise in the head and neck region and oral cavity is the most frequent subsite [2]. SFT in the larynx is rare and about 17 cases have been reported in the literature. Subglottic SFT is even more rare and to the best of our knowledge , ours is the $3^{\text {rd }}$ case being reported $[7,8]$.

Most of the laryngeal SFTs occur in the middle age, though one has been reported in a 13 year old boy [10]. It is predominant in males, usually presenting as a slow growing painless lesion with a variable degree of obstructive symptoms, hoarseness , foreign body sensation etc. Though SFTs behave like benign lesion, complete resection is recommended to prevent local recurrence $[6,11]$. Pabayos GS et al., reported a case of SFT involving supraglottic larynx and presenting as an anterior neck mass, probably expanding through the cricothyroid membrane. It was termed as benign although it had extended to the anterior neck, as there was no involvement of thyroid gland, strap muscle, absence of thyroid cartilage erosion and there were no malignant histological features seen [12].

Endoscopic appearance is that of a submucosal smooth vascular lesion, arising from the epiglottis, aryepiglottic fold, false cord, true cord $[9,11]$, or rarely from the subglottis $[7,8]$, as in our case.

Radiologically, laryngeal SFTs appear intensely enhancing polypoidal lesions on CT and MRI due to their rich vascularity and may partially or completely occlude the laryngeal lumen. Less enhancing areas of SFT pathologically correlate with myxoid or cystic degeneration [5]. On MRI, they are of intermediate intensity on $\mathrm{T} 1$-weighted images and heterogeneously hyperintense on T2-weighted images [4,11,13].
In our case, MRI was not done due to financial constraints. Radiological differential diagnosis of laryngeal SFT includes benign non squamous cell tumors such as hemangiomas, chondromas, chondrosarcomas, leomyomas, leomyosarcomas, rhabdomyomas, rhabdomyosarcomas, lipomas, salivary gland originated tumors and fibrohistiocytic tumors [14]. SFTs, on Dynamic contrast enhanced MRI and dual phased CT, demonstrate rapid and intense enhancement during early phase scanning, followed by a progressive washout of contrast material during delayed phase scanning, which may suggest the possibility of SFT $[4,5]$.

The Diagnosis of SFT is made, based on its histological appearance [13]. Microscopically, SFT is often characterized as a fibrous lesion with a "patternless pattern" with bland spindle cells transected by hyalinized fibrous bands with prominent "hemangiopericytoma-like," branching, thin-walled blood vessels [15-18]. Histological features associated with aggressive behavior like nuclear atypia, markedly increased cellularity, areas of necrosis and greater than 4 mitoses per $10 \mathrm{HPF}$, are rarely encountered in SFTs. The diagnosis of SFT is supported by a characteristic immunohistochemical profile. $C D_{34}$ a $110-\mathrm{kDa}$ transmembrane glycoprotein, which is a kind of myofibroblastic marker, is considered to be the characteristic marker of SFT. In addition, SFTs are also positive for mesenchymal markers like Vimentin. CD99 and BCL-2 protein markers are positive in about $50 \%$ of cases. But they are consistently negative for cytokeratin, alpha-SMA, S-100, and CD31 $[6,15]$.

Surgery is the mainstay of treatment for SFTs. Though , most of the SFTs show a benign course, about $15-20 \%$ of them behave aggressively with local recurrences and distant metastasis. Thus, treatment should be a radical resection or wide resection with clear margins $[6,11]$. Approach can be either trans oral - endoscopic excision with $[7,14,19,20]$, or without CO2 Laser [9], or an external approach with a temporary tracheostomy depending on the site and size of the lesion $[10,11,21]$. Girardi F, et al., in one of their cases, had performed a Total Laryngectomy for laryngeal SFT, considering the patient's age, clinical condition, extensive lesion and history of Radiotherapy treatment for a suspected malignancy [21].

Long term follow up is essential due to the potential malignant transformation as well as to look for local recurrences. Histopathologically, some authors have reported that, low expression or loss of $\mathrm{CD} 34$ and high IGF2 showed a higher statistical correlation to the malignant potential in SFTs than the mitotic index [22].

\section{Conclusion}

Solitary fibrous tumor of the Larynx is a rare disease, posing a diagnostic challenge to the clinicians and pathologists. Diagnosis is based on histopathological features and Immunohistochemical markers. To our best knowledge, this is the third case of subglottic SFT being reported. SFT, though rare can be included as one of the differential diagnosis for benign submucosal laryngeal lesions which enhance intensively . Regular follow up post surgery is necessary to look for local recurrences and possible malignant transformation. 


\section{References}

1. Klemperer P, Rabin CB (1931) Primary neoplasms of the pleura: a report of five cases. Arch Pathol 11: 385-412.

2. Gold JS, Antonescu CR, Hajdu C, Ferrone CR, Hussain M, et al. (2002) Clinicopathologic correlates of solitary fibrous tumors. Cancer 94: 1057-1068. Link: https://bit.ly/2X0I0du

3. Scharifkler D, Kaneko M (1979) Localized fibrous "mesothelioma" of pleura (submesothelial fibroma). Cancer 43: 627-635. Link: https://bit.ly/2yBZF1W

4. Liu Y, Li K, Shi H, Tao X (2014) Solitary fibrous tumours in the extracranial head and neck region: correlation of CT and MR features with pathologic findings. Radiol Med 119: 910-919. Link: https://bit.ly/2TzySKX

5. Kim HJ, Kim HJ, Kim YD, Yim YJ, Kim ST, et al. (2008) Solitary fibrous tumor of the orbit: CT and MR imaging findings. AJNR Am J Neuroradiol 29: 857-862. Link: https://bit.ly/3glrpZz

6. Ganly I, Patel SG, Stambuk HE, Coleman M, Ghossein R, et al. (2006) Solitary fibrous tumors of the head and neck: a clinicopathologic and radiologic review. Arch Otolaryngol Head Neck Surg 132: 517-525. Link: https://bit.ly/2X0wKhs

7. Park SJ, Lee YH, Lee KY, Oh KH, Kim Y (2016) A solitary fibrous tumor of the subglottic larynx: Case report and literature review. Balkan Med J 33: 698-700. Link: https://bit.ly/2AVjqSK

8. Thompson LD, Karamurzin Y, Wu ML, Kim JH (2008) Solitary fibrous tumor of the larynx. Head Neck Pathol 2: 67-74. Link: https://bit.ly/3gnPT4v

9. Selcuk OT, Renda L, Osma U, Suren D, Eyigor H, et al. (2016) Solitary fibrous tumor of the larynx: Literature review and a case presentation. Egyptian Journal of Ear, Nose, Throat and Allied Sciences. 17. Link: https://bit.ly/3d3XL93

10. Safneck JR, guacil-Garcia A, Dort JC, Phillips SM (1993) Solitary fibrous tumour: report of two new locations in the upper respiratory tract. J Laryngol Otol 107: 252-256. Link: https://bit.ly/2XtPoxb

11. Morvan JB, Veyrieres JB, Mimouni O, N'Guyen AT, Fouet B, et al. (2011) Solitary fibrous tumour of the larynx: a case report. Eur Ann Otorhinolaryngol Head Neck Dis 128: 262-265.
12. Pabayos GS, Chiong AM (2019) Solitary Fibrous Tumor of the Larynx and Anterior Neck. Philipp J Otolaryngol Head Neck Surg 34: 64-67. Link: https://bit.ly/36zRnEq

13. Chang SK, Yoon DY, Choi CS, Yun EJ, Seo YL, et al. (2008) CT, MR, and angiography findings of a solitary fibrous tumor of the larynx: a case report. Korean J Radiol 9: 568-571. Link: https://bit.ly/2X0stuo

14. Dotto JE, Ahrens W, Lesnik DJ, Kowalski D, Sasaki C, et al. (2006) Solitary fibrous tumour of the larynx: a case report and review of the literature. Arch Pathol Lab Med 130: 213-216. Link: https://bit.ly/3ejLZrr

15. Chan JK (1997) Solitary fibrous tumor-everywhere, and a diagnosis in vogue Histopathology 31: 568-576. Link: https://bit.ly/36Cgpmb

16. Brunnemann RB, Ro JY, Ordonez NG, et al. (1999) Extrapleural solitary fibrous tumor: a clinicopathologic study of 24 cases. Mod Pathol 12: 1034-1042. Link: https://bit.ly/3gnFXI6

17. Vallat-Decouvelaere AV, Dry SM, Fletcher CD (1998) Atypical and malignant solitary fibrous tumors in extrathoracic locations: evidence of their comparability to intra-thoracic tumors. Am J Surg Pathol 22: 1501-1511. Link: https://bit.ly/2ZEaEml

18. Graadt van Roggen JF, Hogendoorn PCW (2004) Solitary fibrous tumour: the emerging clinicopathologic spectrum of an entity and its differential diagnosis. Curr Diagn Pathol 10: 229-235. Link: https://bit.ly/3ekVPcA

19. Alobid I, Alos L, Maldonado M, Menendez LM, Bernal-Sprekelsen M (2005) Laryngeal solitary fibrous tumours treated with $\mathrm{CO} 2$ laser excision: case report. Eur Arch Otorhinolaryngol 262: 286-288. Link: https://bit.ly/2THFGGt

20. Stomeo F, Padovani D, Bozzo C, et al. (2007) Laryngeal solitary fibrous tumour. Auris Nasus Larynx 34: 405-408. Link: https://bit.ly/2XzhZBn

21. Girardi F, Marinez B, Girardi M (2014) Solitary Fibrous Tumor of the Larynx report of two new cases. J Bras Patol Med Lab 50. Link: https://bit.ly/2ZCrJgF

22. Schulz B, Altendorf-Hofmann A, Kirchner T, Katenkamp D, Petersen I, et al. (2014) Loss of cd34 and high igf2 are associated with malignant transformation in solitary fibrous tumors. Pathol Res Pract 210: 92-97. Link: https://bit.ly/2X6SSa5

\section{Discover a bigger Impact and Visibility of your article publication with}

\section{Peertechz Publications}

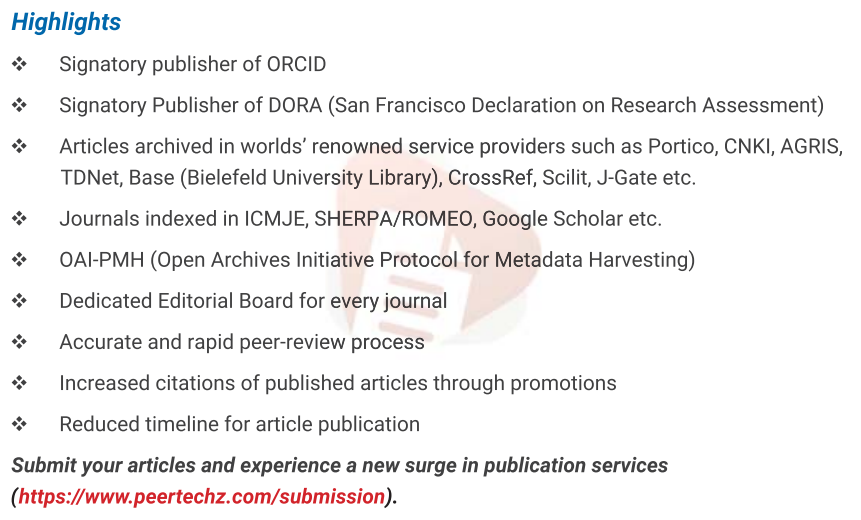

Peertechz journals wishes everlasting success in your every endeavours.

Copyright: ( 2020 Sumana CV, et al. This is an open-access article distributed under the terms of the Creative Commons Attribution License, which permits unrestricted use, distribution, and reproduction in any medium, provided the original author and source are credited. 